\title{
Iogurte adicionado de polpa de abacaxi, base mel: Elaboração, perfil microbiológico e físico-químico
}

\section{Yogurt added pineapple pull, honey base: Development, microbiological profile and physicochemical}

\author{
Yaroslávia F. Paiva ${ }^{1 *}$, José N. V. Deodato ${ }^{2}$ Emerson E. V. da Silva ${ }^{3}$, Everton V da Silva ${ }^{4}$, Alfredina dos S. Araújo ${ }^{5}$
}

\begin{abstract}
Resumo: Os produtos lácteos, são fonte importante para se obter nutrientes necessários para um bom funcionamento do organismo humano. Com o mercado consumidor em alta, sentiu-se a necessidade de adicionar ingredientes que auxiliam tanto na aceitação do produto final, quanto o tornando uma refeição mais nutritiva. Objetivou-se a elaboração de iogurte natural que uniu as propriedades nutritivas do abacaxi e do mel de abelha. As três formulações do produto (A,B e C) foram submetidas à análises microbiológicas (Coliformes à $35^{\circ} \mathrm{C}$ e $45^{\circ} \mathrm{C}$, Salmonella sp/25g., Staphylococcus spp., Contagem total de bactérias aeróbias Mesófilas (CTM) e Psicotróficas) seguindo metodologia descrita por Silva (2010) e à análises físico-químicas (Umidade, Cinzas, Sólidos Solúveis ( $\left.{ }^{\circ} \mathrm{Brix}\right), \mathrm{pH}$, Acidez e Proteínas) utilizando metodologia do Instituto Adolfo Lutz (2008). As três formulações apresentaram ausência emtodos os parâmetros microbiológicos analisados, exceto para CTM, apresentando valores de 1x 10 e 1,5x 10UFC/g, estando dentro dos padrões estabelecidos. Nas análises físico-químicas, esteve dentro dos padrões para acidez $(0.803,0.904$ e 0.934$)$ e proteínas $(2.98,3.75$ e 4.39$)$ e fora dos padrões para ${ }^{\circ}$ Brix $(37.1,37.4$ e 41.5), não existindo padrões específicos para os demais parâmetros. Conclui-se que todas as formulações estão aptas a comercialização, dependendo apenas da preferência sensorial dos consumidores.
\end{abstract}

Palavras-chaves: qualidade, inovação, mel de abelha, produtos lácteos

\begin{abstract}
Dairy products are an important font to obtain nutrients necessary for proper functioning of the human body. In the consumer market for high, felt the need to add ingredients which assist both the acceptance of the final product, as becoming a more nourishing meal. Aimed to the development of natural yogurt that united the nutritional properties pineapple and honey. The three product formulations (A, B and C) were subjected to microbiological tests (Coliformes at $35^{\circ} \mathrm{C}$ and $45^{\circ} \mathrm{C}$, Salmonella sp/25g., Staphylococcus spp., Total count of aerobic bacteria mesophile (CTM) and psicotrophic) following the methodology described by Silva (2010) and physicochemical analysis (humidity, ash, soluble solids $\left({ }^{\circ} \mathrm{Brix}\right)$, pH, acidity and protein) using the methodology of the Adolfo Lutz Institute (2008). All three formulations presented absence in all microbiological parameters analyzed, except for CTM, with values of $1 \times 10$ and $1.5 \times 10 \mathrm{UFC} / \mathrm{g}$, and within established standards. The physico-chemical analysis, was within the standards for acidity $(0803,0904$ and 0934$)$ and protein $(2.98,3.75$ and 4.39) and non-standard for Brix (37.1, 37.4 and 41.5), and there are no specific standards for the other parameters. It is concluded that all formulations are suitable for consumption, depending only on sensory consumer preference.
\end{abstract}

Key words: quality, innovation, bee honey, milk products

\footnotetext{
*Autor para correspondência

Recebido para publicação em 15/11/2015; aprovado em 12/12/2015

${ }_{1}^{1}$ Aluna de Graduação do curso de Engenharia de Alimentos, pela Universidade Federal de Campina Grande, Pombal - PB, Brasil. E-mail: yaroslaviapaiva@gmail.com

${ }^{2}$ Mestre em Sistemas Agroindustriais, pela Universidade Federal de Campina Grande - Pombal, PB. e-mail: jnvdeodato@hotmail.com

${ }^{3}$ Aluno de Graduação em Química, pela Universidade Federal de Campina Grande - Cajazeiras - PB, Brasil. E-mail: emersonfis@ hotmail.com

${ }^{4}$ Aluno de Doutorado em Química, pela Universidade Federal da Paraíba, João Pessoa - PB. Brasil. E-mail: evertonquimica@ hotmail.com

${ }^{5}$ Doutora em Engenharia de Processos, Professora da Universidade Federal de Campina Grande (UFCG), Pombal - Paraíba. e-mail: alfredinad@ hotmail.com
} 


\section{INTRODUÇÃO}

De acordo com Brasil (2007), entende-se por iogurte, produto adicionado ou não de outras substâncias alimentícias, obtidas por coagulação e diminuição do $\mathrm{pH}$ do leite, ou reconstituído, adicionado ou não de outros produtos lácteos, por fermentação láctica mediante ação de cultivos de microorganismos específicos. Estes microorganismos específicos devem ser viáveis, ativos e abundantes no produto final durante seu prazo de validade, cuja fermentação se realiza com cultivos protosimbióticos de Streptococcussalivariussubsp. thermophilus

Lactobacillusdelbrueckiisubsp. Bulgaricus, aos quais se podem acompanhar, de forma

complementar, outras bactérias ácido-lácticas que, por sua atividade, contribuem para a determinação das características do produto final.

O iogurte é um produto altamente recomendado pelas suas características sensoriais, probióticas e nutricionais, por ser rico em proteínas, cálcio e fósforo, conter baixo teor gorduras e fonte de minerais como zinco e magnésio. Seu valor nutricional é superior ao do leite em conteúdo de vitaminas do complexo $\mathrm{B}$, sendo mais facilmente aceito por indivíduos com intolerância à lactose, é recomendado especialmente para gestantes, lactantes, pessoas idosas ou que necessitem de reposição de cálcio (MEDEIROS, 2011)

O grupo de alimentos feitos a base de leite, é uma fonte importante para se obter nutrientes tão necessários para um bom funcionamento do organismo humano. Especificamente para esse tipo de produto, os consumidores declaram escolher o tipo de loja onde encontram uma maior variedade de produtos e ofertas (NIELSEN, 2012). Portanto, com um mercado consumidor em alta, sentiu-se a necessidade de adicionar ingredientes como frutas e alimentos naturais, que auxiliam tanto na aceitação do produto final, quanto o tornando uma refeição mais nutritiva (PAIVA et al., 2014), variando em formas, tamanhos e texturas.

$\mathrm{O}$ abacaxi destaca-se pelo valor energético, devido à sua alta composição de açúcares, e valor nutritivo pela presença de sais minerais (cálcio, fósforo, magnésio, potássio, sódio, cobre e iodo) e de vitaminas (C, A, B1, B2 e Niacina). No entanto, apresenta teor proteico e de gordura inferiores a $0,5 \%$ (ARAÚJO, 2007). Quando comercializado na forma minimamente processada, o abacaxi apresenta um grande potencial, devido às suas características sensoriais e aceitação no mercado consumidor (CHAVES et al., 2011), podendo ser facilmente adicionado à outros alimentos, possuindo as mesmas propriedades nutricionais e organolépticas do fruto in natura.

O mel de abelha é um produto alimentício de grande valor nutritivo e de alta aceitabilidade por parte do consumidor principalmente por ser considerado um produto terapêutico e benéfico à saúde (RACOWSKI, 2009).

Objetivou-se através do presente trabalho, a elaboração e avaliação microbiológica e físico-química de um novo produto, que manteve as características organolépticas dos iogurtes naturais com as propriedades nutritivas do abacaxi e do mel de abelha.

\section{MATERIAL E MÉTODOS}

\section{Elaboração}

Durante a elaboração, todos os ingredientes utilizados foram adquiridos no comércio da cidade de Pombal, Paraíba, sendo posteriormente encaminhados até o Centro Vocacional Tecnológico (CVT), da Universidade Federal de Campina Grande, Campus Pombal.

Para produzir o iogurte natural, inicialmente houve pasteurização do leite a $65^{\circ} \mathrm{C}$, durante 30 minutos, resfriamento a $42,5^{\circ} \mathrm{C}$, adição da cultura láctea e de $4 \%$ de açúcar, seguido de incubação a $42,5^{\circ} \mathrm{C}$ durante 6 horas em estufa. Para a produção da polpa de abacaxi base mel, os frutos foram selecionados, descascados, cortados manualmente em cubos e submetidos à adição do mel em diferentes concentrações (Tabela 1), durante o cozimento, a $37^{\circ} \mathrm{C}$ durante 40 minutos. Após a produção, foram unidos, armazenados em recipientes estéreis e submetidos à refrigeração.

Tabela 1. Formulações obtidas durante a elaboração.

\begin{tabular}{c|c}
\hline Formulações & Descrição \\
A & Iogurte natural $+30 \%$ de mel, 70\% de abacaxi \\
B & Iogurte natural $+40 \%$ de mel, 60\% de abacaxi \\
C & Iogurte natural $+50 \%$ de mel, 50\% de abacaxi \\
\hline
\end{tabular}

Análises Microbiológicas

Após a produção, todas as formulações do produto foram armazenados em recipientes estéreis e submetidos à refrigeração. Em seguida foram analisadas quanto a Coliformes à $35^{\circ} \mathrm{C}$ e à $45^{\circ} \mathrm{C} \quad(\mathrm{NMP} / \mathrm{g})$, Staphylococcusspp.(UFC/g), Salmonella $\mathrm{sp} / 25 \mathrm{~g}$. (presença ou ausência), Contagem total de bactérias aeróbias mesófilas (CTM) (UFC/g) e Contagem total de bactérias aeróbias Psicotróficas (UFC/g), seguindo metodologia descrita por Silva (2010), no Laboratório de Microbiologia de Alimentos (LMA) da Universidade Federal de Campina, Campus
Pombal.

Análises Físico-Químicas

Para as determinações físico-químicas, o produto foi encaminhado após a produção, para o Laboratório de Análises Físico-Químicas, do Centro de Ciências e Tecnologia (CVT), da Universidade Federal de Campina Grande, Campus Pombal. Então, os seguintes parâmetros foram analisados: umidade, cinzas, $\mathrm{pH}$, acidez titulável, sólidos solúveis ( ${ }^{\circ} \mathrm{Brix}$ ) e proteínas, todos realizados em triplicata.Os procedimentos utilizados estão de acordo com a metodologia do Instituto 
Adolfo Lutz (2008). Os dados obtidos foram comparados pelo teste de Tukey ao nível de 5\% de probabilidade.

\section{RESULTADOS E DISCUSSÃO}

Os resultados obtidos nas análises microbiológicas estão dispostos na Tabela 2 a seguir e de acordo com a Resolução 12 da ANVISA (BRASIL, 2001), com padrões estabelecidos, para Coliformes e Samonella sp/25g Não havendo padrões para Staphylococcus spp.,Contagem total de bactérias aeróbias Mesófilas (CTM) e Contagem total de bactérias aeróbias Psicotróficas, porém a análise desses microorganismos indica a qualidade higiênica em que os alimentos foram produzidos e dão ideia sobre o seu tempo útil e temperatura de conservação. Levando em consideração que segundo Sousa (2004), citato por Soares (2009), a grande maioria das bactérias patogênicas de origem alimentar é mesófila, e uma alta contagem de microrganismos mesófilos pode indicar a presença de contaminantes no produto final.

Tabela 2-Resultados obtidos nas análises microbiológicas.

\begin{tabular}{c|ccc}
\hline & A & B & C \\
\hline Coliformes à $35^{\circ} \mathrm{C}$ & Ausente & Ausente & Ausente \\
Coliformes à $45^{\circ} \mathrm{C}$ & Ausente & Ausente & Ausente \\
Staphyococcus spp. & Ausente & Ausente & Ausente \\
Salmonella sp/25g. & Ausente & Ausente & Ausente \\
CTM & 1 x 10 UFC/g & $1,5 x 10$ UFC/g & $1,5 \times 10$ UFC/g \\
Psicotróficos & Ausente & Ausente & Ausente \\
\hline
\end{tabular}

Todas as amostras apresentaram-se dentro dos padrões estabelecidos para Coliformes à $45^{\circ} \mathrm{C}$ e Samonella sp/25g. Resultados muito próximos também para Coliformes à $45^{\circ} \mathrm{C}$ foram encontrados por Moraes et al. (2002), (máximo de 1 $\mathrm{NMP} / \mathrm{g}$ ), Rocha et al.(2008) (<0,3 a 3,0 NMP/g) e Medeiros et al.(2011) (menos que 3,0 NML/g). Esses mesmos autores também encontraram ausência de Samonella sp/25g,o que comprova correta manipulação e higiene em todos os processos de produção, garantindo um alimento seguro quanto à presença de coliformes e de patógenos entéricos.

A ausência de Staphylococcus spp. evidencia mais uma vez, a qualidade microbiológica do produto e correta pasteurização.
Os resultados para Contagem Total de bactérias Aeróbias Mesófilas (CTM), não diferiram muito entre as formulações e apresentaram valores consideravelmente menores que os encontrados por Moreira et al. (1999) e Oliveira et al. (2013), com valores variando de $1,2 \times 10^{7}$ a $8,8 \times 10^{7}$ e $7 \times 10^{3}$ a 2,1 $\times 10^{5} \mathrm{UFC} / \mathrm{g}$, respectivamente. Os baixos índices de CTM observados e à ausência de Psicotróficos, demonstram que o produto pode ser armazenado tanto em temperaturas intermediárias, quanto em baixas temperaturas, sendo melhor conservado em refrigeração constante.

A Tabela 3 a seguir, apresenta os resultados obtidos nas análises físico-químicas.

Tabela 3-Resultados obtidos nas análises físico-químicas.

\begin{tabular}{c|cccccc}
\hline Formulações & Umidade & Cinzas & pH & Acidez & $\begin{array}{c}\text { Sólidos } \\
\text { Solúveis } \\
\left({ }^{\mathbf{0}} \text { Brix }\right)\end{array}$ \\
\cline { 2 - 7 } A & $79,7^{\mathrm{a}}$ & $0,99^{\mathrm{a}}$ & $3.76^{\mathrm{a}}$ & $0,803^{\mathrm{a}}$ & $37,1^{\mathrm{a}}$ & $2,98^{\mathrm{a}}$ \\
B & $79,6^{\mathrm{a}}$ & $0,94^{\mathrm{a}}$ & $3.82^{\mathrm{a}}$ & $0,904^{\mathrm{a}}$ & $37.4^{\mathrm{b}}$ & $4,39^{\mathrm{b}}$ \\
$\mathbf{C}$ & $76,4^{\mathrm{b}}$ & $0,75^{\mathrm{b}}$ & $3.78^{\mathrm{a}}$ & $0,934^{\mathrm{b}}$ & $41,5^{\mathrm{b}}$ & $3,75^{\mathrm{c}}$ \\
\hline
\end{tabular}

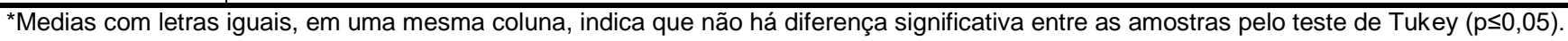

As três formulações diferiram significativamente pelo teste de Tukey $(\mathrm{p} \leq 0,05)$ nos parâmetros de umidade, cinzas, acidez, sólidos solúveis e proteínas. Sendo assim, apenas para $\mathrm{pH}$, os valores não diferiram.

$\mathrm{Na}$ análise de umidade os valores foram de 76,4, 79,6 e 79,7 , não existindo legislação que prevê padrões para o parâmetro analisado.

$\mathrm{O}$ teor de cinzas de um alimento representa a quantidade de minerais nele contidos, onde os valores encontrados 0,75 , 0,94 e 0,99 diferiram significativamente entre si. Valor menor foi encontrado por Martins et al. (2013), avaliando iogurte elaborado com extrato hidrossolúvel de soja e suplementado com inulina, sendo de 0,48. Borges et al (2009) encontrou valores inferiores aos encontrados no atual trabalho, variando entre 0,25 e 0,71 para iogurtes de leite bovino e bubalino sabor cajá, respectivamente. Os altos teores de cinzas encontrados nesse trabalho correspondem a grande quantidade de minerais contidos no abacaxi e no mel de abelha.

Os valores de $\mathrm{pH}$ não diferiram entre si, com pequena variação de 3,76 à 3,82 . Apesar de não existir legislação específica para esse parâmetro, alguns autores como Finco et al (2011) e Medeiros et al (2011), encontraram valores de 4,64 e 4,00, em iogurtes enriquecidos com farinha de 
gergelim e iogurtes de jaca, respectivamente. Valores esses, relativamente maiores que os encontrados nesse trabalho, o que deve está ligado à alta acidez da matéria-prima utilizada, nesse caso, os abacaxis.

A acidez em todas as formulações variou de 0,803 à 0,934, apresentando-se dentro do limite permitido pela legislação, que é de, no mínimo, $0,6 \mathrm{~g}$ de ácido láctico $/ 100 \mathrm{~g}$ de iogurte e, no máximo, $1,5 \mathrm{~g}$ de ácido láctico/100g de iogurte (BRASIL, 2000). Cunha Neto e seus colaboradores (2005) encontraram valores de acidez variando entre 1,12 e 1,17 em iogurte natural produzido com leite de búfala em diferentes classificações, como desnatado, integral e padronizado. Valores encontrados por Borges et al (2009) em iogurtes sabor cajá, produzidos a partir de leite bovino e de bubalino, também estiveram de acordo com a legislação, com valores de 0,947 e 0,984 , respectivamente.

Os teores de sólidos solúveis variaram entre 37.1, 37.4, e $41.5^{\circ}$ Brix respectivamente, estando fora dos padrões designados pela legislação que estabelece um valor de 15 a 18 ${ }^{\circ}$ Brix, todavia esses altos teores podem ser justificados pelo uso do mel como matéria-prima, sendo que o aumento gradativo estive diretamente ligadoa quantidade de mel utilizada nas formulações.

Os resultados obtidos mostraram que o teor de proteínas das amostras de todas as formulaçõesapesar da considerável diferença, se encontram de acordo com a legislação, que prevê um mínimo de $2,9 \%(\mathrm{~g} / 100 \mathrm{~g})$ de proteína (BRASIL, 2000). Teores maiores $(4,83$ e 4,97) foram encontrados por Medeiros et al (2011) e por Cunha Neto et al (2005), sendo de 4,77 e 5,50 .

\section{CONCLUSÕES}

A partir dos resultados obtidos foi possível observar que as três formulações de iogurtes com polpa de abacaxi, base mel desenvolvidas apresentaram ótimos resultados referentes aos parâmetros microbiológicos analisados, o que demonstra correta manipulação durante sua produção.Apesar da não significância entre a formulação C (50\% de mel e 50\% de abacaxi) e as demais, em relação aos parâmetros físicoquímicos, exceto para o $\mathrm{pH}$, todos os iogurtes apresentaram potencialidade como opção de comercialização, dependendo apenas da preferência sensorial dos consumidores.

\section{REFERÊNCIAS BIBLIOGRÁFICAS}

BORGES, K. C.; MEDEIROS, A. C. L. de.; CORREIA, R. T. P.; Iogurte de leite de Búfala sabor Cajá (SPONDIAS LUTEA L.): Caracterização físico-química e aceitação sensorial entre indivíduos de 11 a 16 anos.Alim. Nutr., Araraquara. v.20, n.2, p. 295-300, abr./jun. 2009.

BRASIL. Ministério da Agricultura, Pecuária e Abastecimento. Regulamento técnico de identidade e qualidade de leites fermentados.Instrução Normativa $\mathrm{N}^{\mathbf{0}}$ 46, de 23 de outubro de 2007.

BRASIL. Ministério da Agricultura, Pecuária e Abastecimento. Resolução n.5 de 13 de Novembro de 2000. Dispõe sobre o regulamento Técnico de Identidade e Qualidade de Leites Fermentados.
BRASIL. Ministério da Saúde, Agência Nacional de Vigilância Sanitária. Resolução RDC 12, de 02 de janeiro de 2001. Regulamento técnico sobre padrões microbiológicos para alimentos.

CHAVES, K. F.; et al. Características físico-químicas e aceitação sensorial de abacaxi 'Pérola'minimamente processado adicionado com antioxidantes.Tecnol. \&Ciên. Agropec., João Pessoa, v.5, n.1, p.35-39, mar. 2011.

CUNHA NETO, O. C.; et al. Avaliação físico-química e sensorial de iogurte natural produzido com leite de Búfala contendo diferentes níveis de gordura. Ciênc. Tecnol. Aliment., Campinas, 25(3): 448-453, jul.-set. 2005.

FINCO, A. M. de O. et al.; Elaboração de iogurte com adição de farinha de gergelim. Ambiência Guarapuava (PR). v.7 n.2 p. 217 - 227 Maio/Ago. 2011.

INSTITUTO ADOLFO LUTZ. Normas analíticas do Instituto Adolfo Lutz: métodos químicos e físicos para análises de alimentos. v. 1, 3. Ed. São Paulo, 2008.

MARTINS, G. H..;et al. Perfil físico-químico, sensorial e reológico de iogurte elaborado com iogurte com extrato hidrossolúvel de soja e suplementado com insulina. Revista Brasileira de Produtos Agroindustriais, Campina Grande, v.15, n.1, p.93-102, 2013.

MEDEIROS, T. C; et al. Elaboração de iogurte de jaca: Avaliação físico-química, microbiológica e sensorial. Scientia Plena 7, 091502, 2011.

MORAES, C. M; et al. Qualidade microbiológica do iogurte comercializado na cidade de Pelotas. XXIX Congresso Brasileiro de Medicina Veterinária, 2002, Gramado.

MOREIRA, C. M; et al. Análise microbiológica e química de iogurtes comercializados em Lavras - MG. Ciênc. Tecnol. Aliment. vol.19 n.1 Campinas, 1999.

NIELSEN. Variedade, preço e orfertas definem compras de lácteos na América Latina. Disponível em: www.nielsen.com/br/pt/insights/news/2012/variedadepreco-e-ofertas-definem-compras-de-lacteos-naamerica-latina.html

OLIVEIRA, F. M.; et al. Avaliação microbiológica e físicoquímica de iogurtes de morango industrializados e comercializados no município de Linhares - ES. Ver. Brasileira de Produtos Agroindustriais, Campina Grande, v.15, n.2, p.156, 2013.

PAIVA, Y. F.; et al.; Avaliação microbiolófica de iogurte natural com polpa de abacaxi base mel. Caderno Verde de Agroecologia e Desenvolvimento Sustentável Dezembro, 2014. VOL. 4. No. 1.

RACOWSKI, i. et al.Ação Antimicrobiana do Mel em Leite Fermentado. Revista Analytica. No 30. 106-114 p. Agosto/Setembro 2009. 
ROCHA, C.R.; et al. Elaboração e avaliação de iogurte sabor frutas do cerrado. Boletim do Ceppa, 26, 2: 255-266 (2008).

SILVA, N. da J. et al. Manual de Métodos de Análise Microbiológica de Alimentos e Água. $4^{\circ}$ edição. São Paulo: VARELA, 2010.

SOARES, K. M. P.; et al. Qualidade microbiológica de bebidas lácteas comercializadas no município de Mossoró-RN. UFERSA, Mossoró-RN, 2009.

SOUZA, B. A; et al. Avaliação microbiológica de amostras de mel de trigoníneos (Apidae: Trigonini) do Estado da Bahia. Ciência e Tecnologia de Alimentos, Campinas, 29(4): 798-802, out.-dez. 2004. 